\title{
Tetrapropylammonium Tribromide - An Efficient Reagent for Solvent-Free Brominations
}

\author{
ALIMENLA B $^{1}$, BERNADETTE KUOTSU ${ }^{1,2}$ and UPASANA B. SINHA ${ }^{* 1}$ \\ ${ }^{1}$ Department of Chemistry, Nagaland University, Lumami-798627, Nagaland, India \\ ${ }^{2}$ Department of Chemistry, Kohima Science College, Jotsoma, Kohima, Nagaland, India \\ upasanaborasinha@gmail.com
}

Received 10 December 2013 / Accepted 2 January 2014

\begin{abstract}
Tetrapropylammonium tribromide (TPATB) has been synthesized by a new environmentally benign protocol and its behavior as brominating reagent under solvent-free conditions studied. The reagent shows efficiency as a solvent-free brominating agent in both hotair oven at elevated temperature as well as in microwave reactor, thus proving it to be a noteworthy addition to the existing organic tribromide reagents.
\end{abstract}

Keywords: Tetrapropyl ammonium tribromide, Bromination, Solvent-free, Microwave

\section{Introduction}

Growing environmental concern has made solvent-free chemical synthesis very important. Again, in current times, quaternary ammonium tribromides (QATBs) are becoming a small yet important group of reagents for organic transformations. Because of their ease of formation, mildness, environmental benignity and immense versatility, these reagents have become quite popular and a number of reports are available discussing the importance of these reagents in various types of organic transformations ${ }^{1-19}$, such as bromination reactions ${ }^{1-10}$, acylations ${ }^{11-14}$, sulfide oxidations ${ }^{15-16}$ among others. Because of this versatility, even existing QATBs need to be further explored and therefore, development of improved synthetic protocols for already existing quaternary ammonium tribromides has also got an importance of its own ${ }^{20-27}$. As case in point, tetrapropylammonium tribromide (TPATB) had been earlier reported but only scanty information with regard to this reagent could be obtained, revealing earlier methods of preparation of TPATB using carbonyl bromide ${ }^{28}$ under $\mathrm{N}_{2}$ and also bromine $^{29}$.

Considering that TPATB is the sister reagent of the very versatile tetrabutylammonium tribromide (TBATB), it is expected that the reagent will have the potential to show efficacy for a number of reactions and accordingly, an alternative, environmentally benign method of synthesis was designed, involving hydrogen peroxide - sodium carbonate oxidant system. Thereafter, an assessment on the efficacy of this compound as a brominating agent under 
solvent-free reaction conditions was carried out using a hot air oven and a microwave reactor. This paper reports the details of the synthetic protocol of tetrapropylammonium tribromide (TPATB) and results of bromination reactions with TPATB under solvent-free reaction conditions.

\section{Experimental}

All reagents of highest purity were purchased from commercial sources and used without further purification. Melting points were determined in open capillaries and are uncorrected. UV/Visible spectra were recorded in Perkin Elmer Lambda 25 spectrophotometer using acetonitrile as solvent. Crystal data were collected with a Bruker Smart Apex-II CCD diffractometer using graphite monochromated MoKa radiation $\left(1=0.71073 \mathrm{~A}^{\circ}\right)$ at $298 \mathrm{~K}$. The completion of organic reactions was monitored by TLC.

\section{Synthesis of tetrapropylammonium tribromide (TPATB)}

$0.057 \mathrm{~g}(0.53 \mathrm{mmol})$ Sodium carbonate $\mathrm{Na}_{2} \mathrm{CO}_{3}$ was added to $50 \% \mathrm{H}_{2} \mathrm{O}_{2}(10 \mathrm{~mL}$; $175.95 \mathrm{mmol}$ ) and the mixture was stirred at room temperature for about 5 minutes until $\mathrm{Na}_{2} \mathrm{CO}_{3}$ completely dissolved and the solution attained a clear colourless solution. To this was added a solution of $5 \mathrm{~g}(18.796 \mathrm{mmol})$ tetrapropyl ammonium bromide, TPAB, $\left(\mathrm{C}_{3} \mathrm{H}_{7}\right)_{4} \mathrm{NBr}$ and $3.7 \mathrm{~g}(31.90 \mathrm{mmol})$ potassium bromide $(\mathrm{KBr})$, both dissolved in $50 \mathrm{~mL}$ of water. To the resultant reaction mixture, $50 \mathrm{~mL}$ of $2 \mathrm{M} \mathrm{H}_{2} \mathrm{SO}_{4}$ was added in small portions, upon which the precipitate appeared immediately. The mixture was allowed to be stirred for further $1 \mathrm{~h}$ whereby a bright yellow coloured compound precipitated out completely. The compound was filtered under suction using Whatman-40 filter paper and dried in vacuum desiccator using self-indicating coarse silica gel. It was further recrystallized in acetonitrile, isolated by suction filtration and dried in vacuo. The yield of the isolated compound was $7.286 \mathrm{~g}(91 \%)$ and melting point was $123-125^{\circ} \mathrm{C}$.

\section{Solvent-free brominations in hot air oven using TPATB}

In a typical reaction, $2 \mathrm{mmol}$ of the chosen substrate and TPATB $(2 \mathrm{mmol})$ were taken in the ratio $1: 1$ on a petridish. The reaction mixture was mixed thoroughly. The petridish containing the reaction mixture was then placed in a hot air oven maintaining a precontrolled temperature of $60 \pm 5^{\circ} \mathrm{C}$. The progress of the reaction was monitored through thin layer chromatographic technique. When TLC detected no further change in reaction profile, the reaction mixture was diluted with $30 \mathrm{~mL}$ ethyl acetate and filtered through a small pad of silica gel to remove the spent reagent. The crude product thus obtained was subjected to column chromatography by using ethyl-acetate - hexane solvent system (volume ratio varied for different substrate) to afford the pure products which are presented in Table 1. The products were identified by comparison of their IR and NMR spectra with those of authentic samples.

\section{Microwave-induced solvent-free brominations using TPATB}

A homogeneous mixture of substrate and reagent in 1:1 ratio was taken in a $50 \mathrm{~mL}$ round bottomed flask. The reaction mixture was mixed thoroughly. The neck of the flask was covered with a small funnel to prevent the spreading of reaction mixture, and then placed inside a microwave monomode reactor (Synthewave $402^{\circledR}$ Prolabo). The reactor was switched on with a controlled power P-40 with corresponding temperature of $90{ }^{\circ} \mathrm{C}$. The progress of reaction was monitored as usual by thin layer chromatography on silica gel $\mathrm{F}_{254}$ by using ethylacetate-hexane solvent system (volume ratio varied for different substrates) 
and the procedure was led to completion in the same manner as for the reactions conducted in the hot air oven, and the products obtained are presented in Table 1. The products were identified by comparison of their IR and NMR spectra with those of authentic samples.

Table 1. Solvent-free bromination reactions on organic substrates using TPATB

\begin{tabular}{|c|c|c|c|c|c|c|}
\hline \multirow[t]{2}{*}{ S.No. } & \multirow{2}{*}{ Substrate } & \multirow{2}{*}{ Product } & \multicolumn{2}{|c|}{$\begin{array}{l}\text { Reactions in hot- } \\
\text { air oven }\end{array}$} & \multicolumn{2}{|c|}{$\begin{array}{c}\text { Microwave- } \\
\text { induced reactions }\end{array}$} \\
\hline & & & Time $^{\mathrm{a}}$ & Yield $^{b}$ & Time $^{\mathrm{a}}$ & Yield $^{b}$ \\
\hline 1 & & & $20 \mathrm{~min}$ & $75 \%$ & $65 \mathrm{~s}$ & $81 \%$ \\
\hline 2 & & & $25 \mathrm{~min}$ & $43 \%$ & $90 \mathrm{~s}$ & $55 \%$ \\
\hline 3 & & & $40 \mathrm{~min}$ & $65 \%$ & $120 \mathrm{~s}$ & $72 \%$ \\
\hline 4 & & & $45 \mathrm{~min}$ & $60 \%$ & $145 \mathrm{~s}$ & $62 \%$ \\
\hline 5 & & & $17 \mathrm{~min}$ & $75 \%$ & $75 \mathrm{~s}$ & $78 \%$ \\
\hline 6 & & & $15 \mathrm{~min}$ & $68 \%$ & $6 \mathrm{~min}$ & $75 \%$ \\
\hline 7 & & & $20 \mathrm{~min}$ & $75 \%$ & $90 \mathrm{~s}$ & $82 \%$ \\
\hline 8 & & & $15 \mathrm{~min}$ & $78 \%$ & $65 \mathrm{~s}$ & $80 \%$ \\
\hline 9 & & & $18 \mathrm{~min}$ & $82 \%$ & $75 \mathrm{~s}$ & $88 \%$ \\
\hline 10 & & & $35 \mathrm{~min}$ & $48 \%$ & $4 \min$ & $55 \%$ \\
\hline 11 & & & $25 \mathrm{~min}$ & $65 \%$ & $180 \mathrm{~s}$ & $72 \%$ \\
\hline 12 & & & $15 \mathrm{~min}$ & $78 \%$ & $60 \mathrm{~s}$ & $90 \%$ \\
\hline 13 & & & $30 \mathrm{~min}$ & $68 \%$ & $135 \mathrm{~s}$ & $75 \%$ \\
\hline 14 & & & $30 \mathrm{~min}$ & $72 \%$ & $120 \mathrm{~s}$ & $75 \%$ \\
\hline
\end{tabular}

${ }^{a}$ Reaction monitored by TLC; ${ }^{b}$ Isolated yield 


\section{Results and Discussion}

Tetrapropylammonium tribromide, $\left(\mathrm{C}_{3} \mathrm{H}_{7}\right)_{4} \mathrm{NBr}_{3}$, TPATB was isolated as a bright yellow compound and recrystallization from acetonitrile gave orange-yellow crystals with melting point of $123-125{ }^{\circ} \mathrm{C}$ (lit.124-126 ${ }^{\circ} \mathrm{C}$ ) ${ }^{28}$. Crystal data of the compound were collected with a Bruker Smart Apex-II CCD diffractometer using graphite monochromated MoKa radiation $\left(1=0.71073 \mathrm{~A}^{\circ}\right)$ at $298 \mathrm{~K}$, revealing an independent tetrapropylammonium ion and an independent, nearly symmetric and linear tribromide ion having $\mathrm{Br} 1-\mathrm{Br} 2$ bond length of 2.5317 and $\mathrm{Br} 2-\mathrm{Br} 3$ bond length of 2.5141 and $\mathrm{Br} 1-\mathrm{Br} 2-\mathrm{Br} 3$ bond angle of 179.55 (Figure 1) having unit cell parameters a 7.8166(5), b 8.9127(5) and c 13.1623(7) [CCDC 942201].
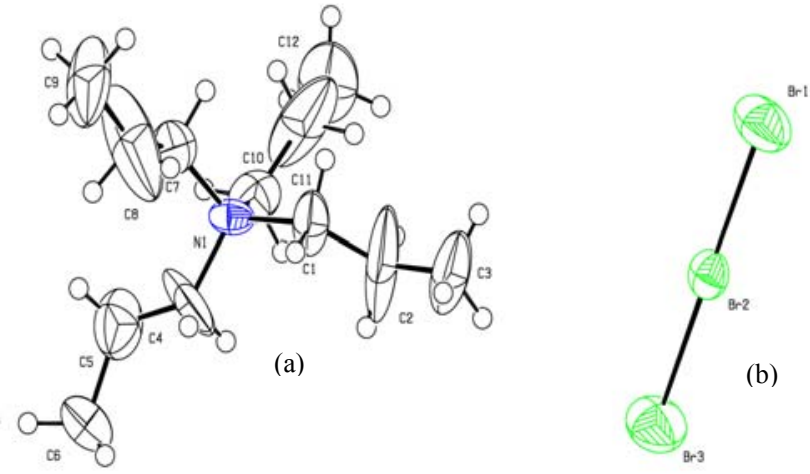

Figure 1. (a) ORTEP view of TPATB with atom numbering scheme; (b) TPATB crystals

Bromination of organic substrates is of significant interest due to the increasing commercial importance of bromo-organics in the synthesis of a large number of natural products as well as in the manufacture of pharmaceuticals, agrochemicals and other specialty chemicals. Bromo-organics are also key intermediates in the preparation of organometallic reagents and play vital roles in transition metal coupling reactions. Bromoorganics can also be used as potent antitumor, antibacterial, antifungal, antineoplastic, antiviral and antioxidizing agents. Acknowledging the importance of bromoorganic compounds ${ }^{30-32}$ and the on-going search for environmentally benign brominating reagents which work well under solvent-free conditions, an attempt was made to study the efficacy of tetrapropylammonium tribromide (TPATB) in alternative reaction conditions avoiding the use of solvents. Accordingly, the reaction systems thus selected were hot air oven and microwave reactor.

Since the alternative reaction conditions required higher temperature, it was considered essential to first do a thermogravimetric analysis of the compound. Thermo gravimetric analysis of tetrapropylammonium tribromide (TPATB) revealed that the compound is stable even up to $c a .200{ }^{\circ} \mathrm{C}$, which implies that the reagent can be used in solvent-free reactions within $200{ }^{\circ} \mathrm{C}$, without any decomposition of the reagent. Thermogravimetric (TG) experiments were conducted on a Perkin Elmer STA -6000 (Simultaneous Thermal Analyser) 521A7091405 instrument. Experiments were done using silica crucibles. Pure $\mathrm{N}_{2}$ gas was used as the flow gas Figure 2.

Solvent-free bromination reactions were possible using tetrapropylammonium tribromide (TPATB) as reagent, both at elevated temperature in a hot-air oven as well as under microwave conditions (Table 1). 


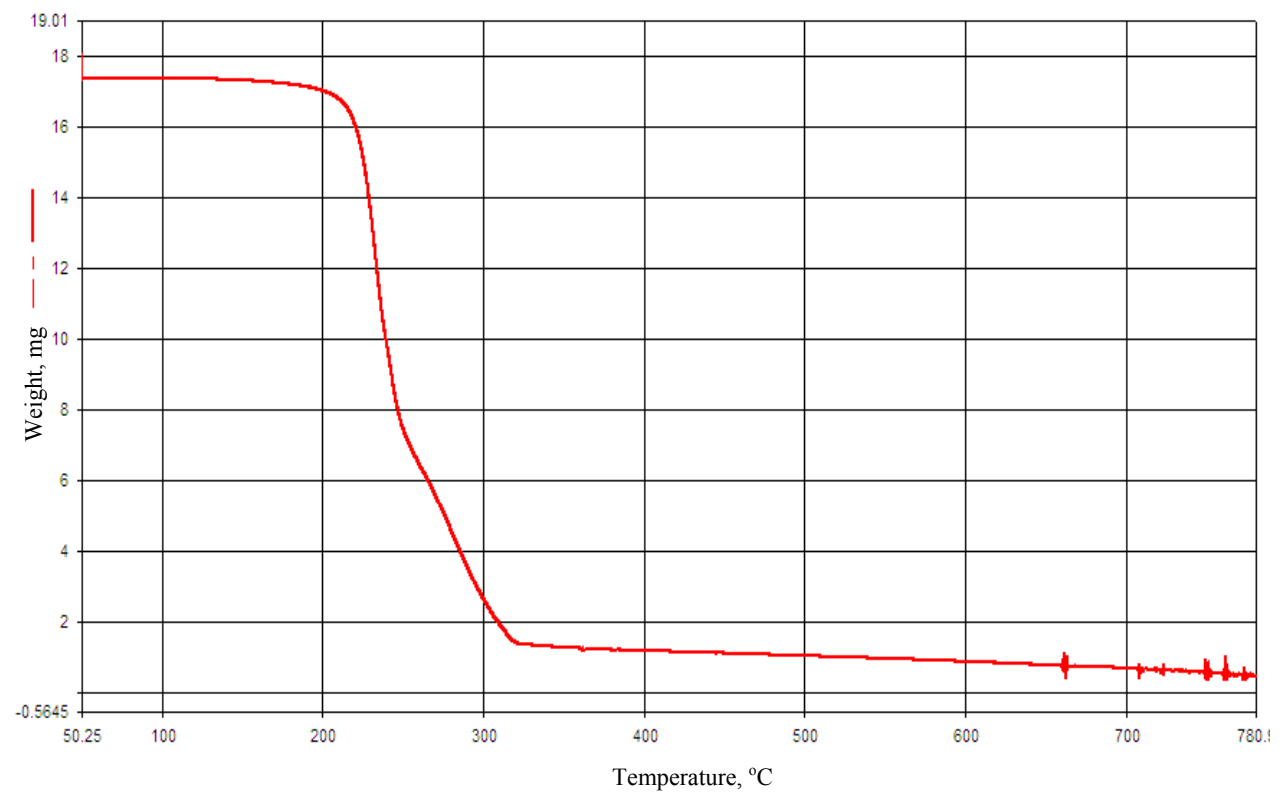

Figure 2. Thermogram of TPATB

Table 1 reveals that with aromatic amino compounds such as aniline, 4-nitroaniline and acetanilide (entries 1 to 3), regioselectivity was maintained and monobrominated products were formed in moderate to high yields. 2-Fluoro aniline also afforded the corresponding bromo-product (4a) in both reaction conditions. Solvent-free bromination reactions were also performed on phenol and some of its derivatives (entries 5-11). In case of cresol, probably the higher $o, p$-directing power of the $\mathrm{OH}$ substituent led to regioselective formation of only monobromo product. A naphthol, which is a fused ring phenolic compound (entry 7) afforded the expected bromo-products in good yields, while a deactivated compound (entry 10) also yielded to bromination, giving the product in moderate yield. For multiple bonded systems (entries 12-14) the corresponding transproducts were obtained in moderate to high yields.

\section{Conclusion}

We reports a very green and inexpensive method of preparation of tetrapropylammonium trtibromide using hydrogen peroxide-sodium carbonate solution. Also reports green protocols for instantaneous, facile and regiospecific bromination of different classes of organic compounds under solvent-free reaction conditions. According to the results obtained, the reactions were facile in both microwave reactor as well as hot-air oven and identical products were formed in both reaction conditions, however, comparing between the two methodologies, it was clearly obvious that reactions in microwave reactor are superior in terms of time and product yield.

\section{Acknowledgement}

The authors are grateful to Dr. R.C. Barua and Dr. P.J. Bhuyan of NEIST Jorhat for extending some facilities for the work. Gratitude is also expressed to Mr. Babulal of IIT Guwahati for recording the X-ray spectrum. The investigation has enjoyed financial support from DST, New Delhi (No.SR/S1/IC-52/2003). 


\section{References}

1. Kavala V, Naik S and Patel B K, J Org Chem., 2005, 70(11), 4267-4271;

DOI:10.1021/jo050059u

2. Chiappe C, Leandri E and Pieraccini D, J Chem Soc Chem Commun., 2004, 25362537; DOI:10.1039/B410796A

3. Singhal S, Jain S L and Sain B, J Mol Catal A: Chem., 2006, 258(1-2), 198-202; DOI:10.1016/j.molcata.2006.05.042

4. Chaudhuri M K, Bora U, Dehury S K, Dey D, Dhar S S, Kharmawphlang W, Choudary M B and Mannepalli L K, 2004, WO, 2004/054962 A1.

5. Chaudhuri M K, Khan A T, Patel B K, Dey D, Kharmawophlang W, Lakshmiprabha T R and Mandal G C, Tetrahedron Lett., 1998, 39(44), 8163-8166;

DOI:10.1016/S0040-4039(98)01818-8

6. Bora U, Chaudhuri M K, Dey D and Dhar S S, Pure Appl Chem., 2001, 73(1), 93.

7. Salazar J and Dorta R, Synlett., 2004, 07, 1318-1320; DOI:10.1055/s-2004-825598

8. Lee J C, Park J Y, Yoon S, Bae Y Y H and Lee S J, Tetrahedron Lett., 2004, 45(1), 191-193; DOI:10.1016/j.tetlet.2003.10.133

9. Alimenia B, Kumar A, Jamir L, Sinha D and Sinha U B, Rad Eff Def Sol., 2006, 161, 687.

10. Bernard A, Kumar A, Jamir L, Sinha D and Sinha U B, Acta Chim Slov., 2009, 56, 457.

11. Gopinath R, Haque S J and Patel B K, J Org Chem., 2002, 67(16), 5842-5845; DOI:10.1021/jo025701o

12. Naik S, Gopinath R and Patel, B K, Tetrahedron Lett., 2001, 42(43), 7679-7681; DOI:10.1016/S0040-4039(01)01599-4

13. Naik S, Kavala V, Gopinath R and Patel B K, Arkivoc, 2006, (i), 119-127.

14. Kavala V and Patel B K, Eur J Org Chem., 2005, 2, 441-451;

DOI:10.1002/ejoc.200400584

15. Kar G, Saikia A K, Bora U, Dehury S K and Chaudhuri M K, Tetrahedron Lett., 2003, 44(24), 4503-4505; DOI:10.1016/S0040-4039(03)01015-3

16. Jordan A D, Luo C and Reitz A B, J Org Chem., 2003, 68(22), 8693-8696; DOI:10.1021/jo0349431

17. Gosain J and Sharma P K, Proc Indian Acad Sci (Chem Sci.), 2003, 115(2), 135-145.

18. Figueira V B C, Synlett, 2006, 2681; DOI:10.1055/s-2006-950446

19. Jamir L, Alimenla B, Kumar A, Dipak S and Upasana D Sinha, Synth Commun., 2011, 41(1), 147-155; DOI:10.1080/00397910903531912

20. Pourmousavi S A and Salehi P, Acta Chim Slov., 2009, 56, 734-739.

21. Borah R and Thakur A J, Synth Commun., 2007, 37(6), 933-939;

DOI:10.1080/00397910601163794

22. Borikar S P, Daniel T and Paul V, Tetrahedron Lett., 2009, 50(9), 1007-1009; DOI:10.1016/j.tetlet.2008.12.053

23. Jordan A D, Luo C and Reitz A B, J Org Chem., 2003, 68(22), 8693-8696; DOI:10.1021/jo0349431

24. Hajipour A R, Imanieh H and Pourmousavi S A, Synthetic Commun., 2004, 34(22), 4597-4604; DOI:10.1081/SCC-200043274

25. Subramanian K, Suresh S and Asokan K, Chem Eng Comm., 2013, 200(9), 12101219; DOI:10.1080/00986445.2012.742435

26. Mondal E, Sahu P R, Bose G and Khan A T, Tetrahedron Lett., 2002, 43(15), 2843-2846; DOI:10.1016/S0040-4039(02)00345-3

27. Dey M and Dhar S S, Green Chem Lett Rev., 2012, 5(4), 639-642;

DOI:10.1080/17518253.2012.692820 
28. Phillips B A, Fodor G, Gal J, Letourneau F and Ryan J J, Tetrahedron, 1973, 29(21), 3309-3327; DOI:10.1016/S0040-4020(01)93483-0

29. Kume Y and Nakamura D, J Magnetic Res., 1976, 21(2), 235-240;

DOI:10.1016/0022-2364(76)90070-6

30. Gribble G W, Cheml Soc Rev., 1999, 28, 335-336; DOI:10.1039/A900201D

31. Sels B, Vos D D, Buntinx M, Pierard F, Mesmaeker A K and Jacobs P, Nature, 1999, 400, 855; DOI:10.1038/23674

32. Butler A and Walker J V, Chem Rev., 1993, 93(5), 1937-1944;

DOI:10.1021/cr00021a014 